\title{
Content is King: An Analysis of How the Twitter Discourse Surrounding Open Education Unfolded From 2009 to 2016
}

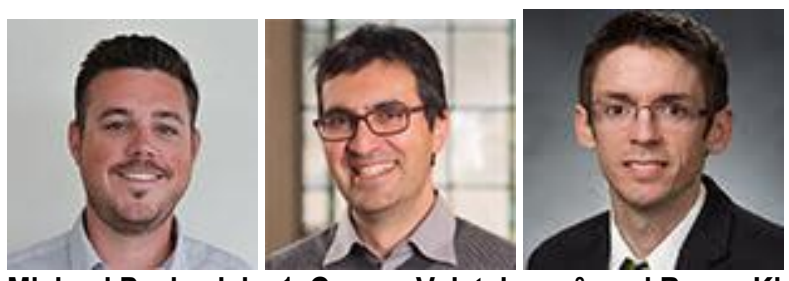

Michael Paskevicius ${ }^{1}$, George Veletsianos ${ }^{2}$, and Royce Kimmons ${ }^{3}$

${ }^{1}$ University of Victoria, ${ }^{2}$ Royal Roads University, ${ }^{3}$ Brigham Young University

\begin{abstract}
Inspired by open educational resources, open pedagogy, and open source software, the openness movement in education has different meanings for different people. In this study, we use Twitter data to examine the discourses surrounding openness as well as the people who participate in discourse around openness. By targeting hashtags related to open education, we gathered the most extensive dataset of historical open education tweets to date ( $n=178,304$ tweets and 23,061 users) and conducted a mixed methods analysis of openness from 2009 to 2016. Findings show that the diversity of participants has varied somewhat over time and that the discourse has predominantly revolved around open resources, although there are signs that an increase in interest around pedagogy, teaching, and learning is emerging.
\end{abstract}

Keywords: open education, open pedagogy, open educational resources, social media research, temporal analysis, Twitter

\section{Introduction}

In recent years, open education has gained significant interest among educational institutions, innovation leaders, and within popular media. Provincial and state governments are supporting open education initiatives; multinational corporations are adopting open practices; and institutions are exploring open textbooks (Pitt, 2015; Bowness, 2017). Given these developments, some authors have noted that, "openness has won" (Weller, 2014, p. 3). Yet, broad familiarity with and implementation of openness in education appears elusive, as surveys show that the majority of faculty do not have a clear understanding of how open education might impact their practice (Belikov \& Bodily, 2016) and current understandings of openness may rely too heavily upon content alone (Kimmons, 2016; Open Educational Quality Initiative [OPAL], 2011). By shifting the focus from content (i.e., open educational 
resources or OER) to the innovative practices made available by using open content, open education may be a catalyst for innovation instead of simply a replacement of traditionally published resources (Deimann \& Farrow, 2013).

This study aims to guide understanding of how the discourse around open education has evolved, which is presently missing from the scholarly literature. Limited understanding of this topic is problematic as understanding how individuals conceptualize openness can provide insight into the trajectory of the open movement, enable us to recognize how stakeholder interest may (or may not) be changing, and allow us to understand interest in, and motivations of, the open education community. In this paper, we use Twitter posts and user profiles as data sources to identify the focal points of social media discourse. A significant advantage of examining social media posts relative to other sources is that social media aggregates the perspectives of a diverse range of individuals including administrators, faculty, researchers, and so forth. Examining 16 hashtags relevant to open education, we were able to identify and retrieve 178,304 tweets, profile information from 23,061 users, and associated metadata. The retrieved data were analyzed using descriptive and qualitative analysis techniques to gain a deeper understanding of the discourse surrounding openness.

\section{Review of Relevant Literature}

Open education has long historical roots, and its development depended not solely on technological advances but also upon social, cultural, and economic developments. Peter and Deimann (2013) cite public lectures, coffee houses, open universities, and the printing press as examples of open education, which existed before the digital age, and openness in education as having been historically framed as a vision of a more inclusive, democratic, collaborative, and flexible form of education.

Open education is now most frequently associated with OER, the designation of which first emerged at a UNESCO forum in 2002. OER include openly licensed and shared educational materials that reside in the public domain or have been released under an intellectual property license that permits their use or re-purposing by others (Atkins, Seely Brown, \& Hammond, 2007). The emergence of a clear and simple licensing mechanism under Creative Commons has been a key factor in the growth and proliferation of OER (Bissell, 2009). OER encompass a range of teaching and learning materials ranging from full courses and individual instructional activities, to modules, assessments textbooks, images, and software. A commonly cited and useful framework to understand OER is offered by Wiley (2007, 2014) in his $5 \mathrm{R}$ framework, which describes the permissions that users should have with respect OER. These include reusing, revising, remixing, redistributing, and retaining.

In this way, advocates propose that OER can "broaden access to education and knowledge, reduce costs, enhance the impact and reach of scholarship and education, and foster the development of more equitable, effective, efficient, and transparent scholarly and educational processes" (Veletsianos \& Kimmons, 2012, para. 2). This emphasis purportedly helps both teachers and students by supporting greater academic freedom and teacher professionalization (Kimmons, 2016) and by fostering creative agency and the co-creation of knowledge artefacts (Hodgkinson-Williams \& Paskevicius, 2012).

While early open education scholarship focused on resources (Wiley, Bliss, \& McEwen, 2014), recent advocacy and research efforts have highlighted openness in other forms, such as open textbooks and open pedagogy (Ehlers \& Conole, 2010; Fischer, Hilton, Robinson, \& Wiley, 2015; Lane \& McAndrew, 
2010). Open textbooks are OER which are collected and formatted like a traditional textbook but that are also made available in digital form with an open license, which allows them to be freely shared, printed, updated, adapted, remixed, etc. Open pedagogy, on the other hand, focuses on the literacies and approaches to teaching and learning that take advantage of the unique affordances of OER - such as one's ability to make a copy of and revise instructional material - and offers new ways to conceptualize the practice of teaching and learning. Open pedagogies further engage students with open culture literacies in the context of teaching and learning, promote the production of knowledge, and often integrate both formal and informal learning environments. Some synonymous terms might be open educational practices (Ehlers \& Conole, 2010) or open literacies (Kimmons, 2014). Attributes of open pedagogy often include the use of participatory technologies; sponsoring of trust; supporting innovation and creativity; greater sharing of ideas and resources; and reflective practice (Hegarty, 2015).

Given so many different perspectives or emphases of openness, it is not surprising that confusion may arise when talking about openness, that scholars may disagree in their emphases (Kimmons, 2016), or that a variety of practitioners may be doing work related to open education for very different reasons (Veletsianos \& Kimmons, 2012). Though open education has a long history and has gained significant awareness and traction in recent years (Hylén, 2006), little research has been conducted on the discourses around open education or what practitioners mean when they say they are doing this sort of work. Fledgling research in understanding the discourses surrounding openness has been confined to six studies, which we will now explore in more detail.

First, Dos Santos (2008) used critical discourse analysis to explore the discourses found on two OER initiative websites. That study examined the language used to describe OER initiatives and discovered that institutional discourses were focused on content provision with an agenda to raise institutional profiles. Although OER was being situated as providing "free access to knowledge," initiatives generally failed to acknowledge the realities of underprivileged contexts that lacked basic resources necessary to make use of the provided OER such as books, writing instruments, classrooms, computers, and skilled instructors. That is, open access is not the same as democratization of knowledge (cf. Kimmons, 2015). Dos Santos (2008) argued that the perceived benefits of making knowledge resources and information available on the internet are not as causal as one might imagine and further explained that open education practitioners should critically examine how their practices are mediated by the discourses of the movement, keeping in mind the varied contexts in which OER may be accessed. While resources may be freely accessed from OER initiative websites, they inevitably come with social, cultural, and linguistic assumptions which may make them challenging to use in other contexts.

Second, Bulfin, Pangrazio, and Selwyn (2014) explored the discourse surroundings the emergence of massive open online courses (MOOCs). MOOCs historically came about as a means for enacting networked and open education, and the authors used news outlets for exploring headlines and article descriptions to understand how these courses were marketed and understood in higher education $(n=$ 457). The authors found that media discourses focused primarily on the economic value of delivering education online to large groups of people, with little consideration for the pedagogical and technological affordances enabled by an open approach, thereby ignoring pedagogical or other transformative aspects of these courses in higher education. 
Third, Kovanović, Joksimović, Gašević, Siemens, and Hatala (2015) conducted programmatic analysis of MOOC discourses upon news and media articles $(n=4,024)$ and found that media coverage of the MOOC phenomenon had decreased rapidly following peaks of interest in 2012-2013. The most popular topics covered by media included references to MOOC service providers; universities offering MOOCs; increased global interest in the phenomenon; and issues pertaining to assessment and accreditation. The use of programmatic analysis in this study, in contrast to traditional discourse analysis, provided an efficient way to surface emergent themes while sacrificing some of the depth associated with qualitative analysis.

Fourth, Kernohan (2015) analyzed 11 years of conference presentation titles from the annual Open Education Conference. He coded the session titles thematically and found that themes represented a multi-faceted, wide ranging, and multidisciplinary discourse. More specifically, annual themes ranged widely over time, expressing concern that the community of open education researchers could improve on building on the findings of previous research and developing more coherence and consistency as a discipline.

Fifth, Weller (2016) explored emergent subcultures within the open education research community by analyzing articles in the OER Knowledge Cloud repository $(n=119)$, an open-access research database with a focus on research relating to open education. The study found that open education research discourses have grown from a narrow set of studies focused on individual projects, to a broad field with several overlapping and complementary themes intersecting with other areas, such as open access publishing, open data, and open citizenship. Weller suggests that while there is emerging evidence of the impact open education is having on the field, there remains less empirical research than one might expect for a maturing discipline.

Finally, Baker (2014) conducted a thematic analysis of Twitter posts which included the \#openeducation hashtag to gain a better understanding of the discourses occurring around open education $(n=903)$. The corpus of tweets was extracted from Twitter using a tool that restricted the researcher's control of statistical sampling, thereby limiting the generalizability of this study. The tweets were analysed and categorized into 32 categories, which spanned eight major themes including information sharing, connections, research, open educational content, open educational designs, change and awareness, open technology, and business promotion. Baker noted that the discourses emerging on Twitter were largely consistent with those being shared in the literature published on open education. These findings suggest that the Twitter discourse related to open education aligned well with scholarly discourse. Given the non-representative sample, further work in this area is necessary.

These studies demonstrate the emergent ways in which researchers are reflecting on the movement towards open education within discourse communities. By reflecting on how open education is being described through the media, literature, public websites, and social media, researchers are able to critically assess how the public may interpret the movement, track emergent themes, and explore changes to the focus and emphasis of the movement over time.

For our purposes, the Kovanović et al., (2015) and Baker (2014) studies are instrumental. The Kovanović et al., (2015) study demonstrates the value of programmatically categorizing information to glean patterns from large sources of data. Baker's (2014) study is instrumental in identifying Twitter participation as a way to make sense of the discourse in the open education community. By combining 
these two aspects of past research, we are able to shed light on the discourse surrounding openness on social media.

\section{Methods}

It is widely recognized that educators, researchers, and open education advocates congregate on Twitter and post content pertaining to open education. The public nature of such comments enables researchers to take an in-depth look at that discourse and identify ways it has or has not changed over time. The use of social media data to make sense of issues facing higher education is an emerging field of study, with some researchers beginning to probe the use of large-scale Twitter analysis as a means for shedding light on matters of scholarly and academic concern (e.g., Kimmons \& Veletsianos, 2016; Kimmons, Veletsianos, \& Woodward, 2016; Veletsianos \& Kimmons, 2016). Such studies demonstrate the diverse ways that academic practitioners use Twitter and highlight the value of analyzing large datasets for examining topics pertaining to education.

In this study, we examined the discourse around openness and its evolution over time from a large Twitter dataset roughly 200 times greater than that utilized by Baker (2014). In doing so, we generated an in-depth picture of the broader open education community over time and addressed limitations in prior studies that examined singular aspects of specific communities.

\section{Research Objectives and Research Questions}

Our intention with this paper is to contribute to a better understanding of the notion of openness using data sourced from Twitter as a vehicle to do so. We posed the following three questions to operationalize and guide our study:

RQ1. How is openness represented on Twitter, and how has participation frequency changed over time?

RQ2. Do we now see more people and a greater diversity of people participating than in the past?

RQ3. How has the Twitter discourse on openness changed over time?

By exploring each of these questions in turn, we hoped to develop a sense for what aspects of openness were being discussed on Twitter (RQ1), how diverse such conversations have been (RQ2), and how trends and norms have historically developed (RQ3).

\section{Data Collection}

By targeting open education hashtags, we were able to identify posts related to open education and their respective authors. The first step involved identifying hashtags relevant to the open education community. We identified these hashtags using a crowdsourced process. A blog post shared on social media and brought to the attention of the open education community invited individuals to contribute hashtags relevant to open education to a publicly-accessible Google spreadsheet. The hashtags contributed by users are identified and described in Table 1 . The next step involved using the Twitter Application Programming Interface (API) and various manual processes described in prior research efforts (e.g., Kimmons \& Veletsianos, 2016; Veletsianos \& Kimmons, 2016), to collect all available tweets and user profile information from the 16 hashtags most pertinent to our research questions. 
The collected dataset consisted of 178,304 tweets and 23,061 users. Metadata associated with tweets (such as the date and time that each tweet was posted) and users (such as the biographical information provided by each user) were also collected.

Table 1

Collected Tweets per Hashtag

\begin{tabular}{|c|c|c|}
\hline Hashtag & $\begin{array}{l}\text { Tweet } \\
\text { count }\end{array}$ & Description \\
\hline \#oer & 140,740 & Open educational resources \\
\hline \#openeducation & 11,436 & Open education \\
\hline \#оер & 6,938 & Open educational practice \\
\hline \#opened15 & 6,478 & Annual Open Education Conference, generally held in North America \\
\hline \#opened14 & 4,946 & Annual Open Education Conference, generally held in North America \\
\hline \#opened13 & 3,126 & Annual Open Education Conference, generally held in North America \\
\hline \#opened12 & 2,836 & Annual Open Education Conference, generally held in North America \\
\hline \#opened11 & 2,086 & Annual Open Education Conference, generally held in North America \\
\hline \#oer11 & 1,131 & $\begin{array}{l}\text { Tweets generated around the annual Open Education Resources } \\
\text { conference generally held in the United Kingdom }\end{array}$ \\
\hline \#go_gn & 1,098 & Global OER Graduate Network \\
\hline \#oerglobal & 919 & Annual Open Education Global conference \\
\hline \#opened10 & 887 & Annual Open Education Conference, generally held in North America \\
\hline \#oer10 & 676 & $\begin{array}{l}\text { Tweets generated around the annual Open Education Resources } \\
\text { conference generally held in the United Kingdom }\end{array}$ \\
\hline \#roer4d & 294 & $\begin{array}{l}\text { Research on Open Educational Resources for Development in Global } \\
\text { South project }\end{array}$ \\
\hline \#openpedagogy & 257 & Open pedagogy \\
\hline \#openped & 160 & Open pedagogy \\
\hline Total Tweets & 178,304 & Some tweets include more than one of the above hashtags \\
\hline
\end{tabular}

\section{Data Analysis}

We employed mixed methods analyses to answer the posed RQs, which varied for each. Descriptive statistics were reported for all RQs, and all questions required some form of qualitative analysis, which was intended (a) to generate some quantitative data (e.g., gender and location of users) and (b) to identify and illustrate various aspects of the discourse surrounding openness (e.g., categories of tweets). Additional specific analysis information is provided in the results section for each specific RQ. 


\section{Results}

Our guiding research question for this study was: How has the discourse surrounding openness unfolded on Twitter? To answer this, we focused on the three secondary research questions listed above. We will now provide results for each of these secondary questions in turn.

\section{RQ1. Openness on Twitter}

To investigate this RQ, we first created three categories under which one can conceptualize openness: education in a general way, content or resources, and practice or pedagogy. These categories were largely identified by the way in which hashtags were described through the crowdsourced process, as contributors were asked to provide a description of how the hashtag was being used within the Twitter community.

Next, we programmatically coded the topical hashtags in the collected tweets as belonging to these three conceptual categories. For example, \#openeducation and \#openlearning as education; \#opencontent, \#oer, and \#openresources as content; and \#openpedagogy, \#oep, and \#openped as practice. Because multiple hashtags could be used in a single tweet, these categories were not exclusive, and overlapping use was also analyzed.

Descriptive analysis of categorized tweets revealed that content hashtags were much more prevalent than were education or pedagogy hashtags at $90.6 \%$ vs. $7.7 \%$ or $4.1 \%$ of the total number of categorized tweets (cf. Table 2). This revealed that most of the conversation related to openness revolved around content rather than education or practice at a rate of about 10 to 1 . Furthermore, a noteworthy portion of education (19.7\%) and practice (21.0\%) tweets also used content hashtags, which revealed that even the tweets belonging to other categories were often connected with the conversations about content. Thus, we concluded that conversations were largely dominated by an emphasis on content rather than other open considerations, such as practice or pedagogy.

Table 2

Tweet Category Frequencies and Overlaps

\begin{tabular}{lccc|ccc|ccc}
\hline & \multicolumn{3}{c|}{ Total number } & \multicolumn{3}{c|}{ Percent of total } & \multicolumn{3}{c}{ Percent of overlap (Y/X) } \\
\hline & \multicolumn{3}{c}{ Education Content } & Practice & \multicolumn{2}{c}{ Education } & Content & Practice & \multicolumn{2}{c}{ Education } & Content & Practice \\
\cline { 2 - 10 } Education & 11,739 & 2,314 & 54 & $7.7 \%$ & $1.5 \%$ & $0.0 \%$ & - & $19.7 \%$ & $0.5 \%$ \\
Content & - & 138,319 & 1,326 & - & $90.6 \%$ & $0.9 \%$ & $1.7 \%$ & - & $1.0 \%$ \\
Pedagogy & - & - & 6,321 & - & - & $4.1 \%$ & $0.9 \%$ & $21.0 \%$ & - \\
\hline
\end{tabular}

One way to conceptualize how participation changed over time was by using the Open Education Conference hashtags (e.g., \#opened10, \#opened11) as proxies for annual participation. An examination of the trend for this conference between 2010 and 2016 revealed that more people had tweeted to the conference hashtag each year, with an annual average increase of $25.8 \%$ per year and a total increase of $205.2 \%$ across the five years following 2010 (cf. Table 3). Tweets per user had also steadily increased in this time period, with an annual average increase of $22.8 \%$ per year and a total increase of $238.8 \%$ across the five years. 
Table 3

Open Education Conference Tweet Frequencies by Year

\begin{tabular}{lcccccc}
\hline Hashtag & Tweets & \% Increase & Users & \% Increase & Tweets per user & \% Increase \\
\hline \#opened10 & 889 & - & 191 & - & 4.7 & - \\
\#opened11 & 2,086 & $134.6 \%$ & 273 & $42.9 \%$ & 7.6 & $64.2 \%$ \\
\#opened12 & 2,825 & $35.4 \%$ & 368 & $34.8 \%$ & 7.7 & $0.5 \%$ \\
\#opened13 & 3,129 & $10.8 \%$ & 476 & $29.3 \%$ & 6.6 & $-14.4 \%$ \\
\#opened14 & 4,947 & $58.1 \%$ & 488 & $2.5 \%$ & 10.1 & $54.2 \%$ \\
\#opened15 & 6,479 & $31.0 \%$ & 583 & $19.5 \%$ & 11.1 & $9.6 \%$ \\
\hline
\end{tabular}

\section{RQ2. Diversity of Participants}

Given this uptake in participation, we also sought to understand the diversity of individuals participating on hashtags associated with openness. The factors that we considered included users' genders, locations (country), account types, and roles. To categorize these four factors, we manually examined users' biographical and metadata information included in their public profiles of a stratified random sample of users $(n=1,014)$, which allowed for generalization with a $95 \%$ confidence level at $+/-3 \%$. Two researchers met five times to conduct this analysis. After initial discussions and collaborative coding, the first researcher coded all the data. Next, the two researchers met to review and discuss the assigned codes. The second researcher, then examined all assigned codes to check for uniform application and to eliminate any potential bias. The information used to code for gender, location, type, and role was as follows:

- Gender was derived from the user name and profile photo or through further following the account URL or conducting a name search. A total of 682 out of the 1,014 accounts were identified as either male (400) or female (282). The gender of the rest of the accounts could not be identified either because it was unclear with the available profile information or due to accounts representing institutions, organizations, etc.

- Location was inferred using the location field data that Twitter users may provide in their profiles. Where user location was unclear, further checks were conducted by following the account URL or by conducting a name search. The locations of 856 accounts (of 1,014) were identified.

- Regarding type, accounts were divided into two groups: individual (686) or organization (227). Accounts were further categorized into roles based on information provided in each account's profile description, account URL, and background search. The assigned codes, descriptions, and prevalence of account roles are shown in Table 4 for individual accounts and Table 5 for organizational accounts. To safeguard privacy, results for individual users are not included or are de-identified in this report. 
Table 4

Individual Accounts Coded

\begin{tabular}{|c|c|c|c|}
\hline Role & Description & Count & $\%$ \\
\hline Educator & $\begin{array}{l}\text { An individual who reports working in K-12 or higher education in an } \\
\text { instructional or research capacity. }\end{array}$ & 210 & $30.61 \%$ \\
\hline $\begin{array}{l}\text { Educational } \\
\text { developer }\end{array}$ & $\begin{array}{l}\text { An individual who reports working as an educational developer, e- } \\
\text { learning developer, faculty developer, instructional designer, or } \\
\text { within a teaching and learning centre. }\end{array}$ & 132 & $19.24 \%$ \\
\hline Other & $\begin{array}{l}\text { An individual whose role could not be determined from available } \\
\text { data. }\end{array}$ & 123 & $17.93 \%$ \\
\hline Corporate & $\begin{array}{l}\text { An individual who reports working outside of education, non-profit, } \\
\text { or government agencies. }\end{array}$ & 112 & $16.33 \%$ \\
\hline Librarian & $\begin{array}{l}\text { An individual who reports working in a K-12 or higher education } \\
\text { library. }\end{array}$ & 41 & $5 \cdot 98 \%$ \\
\hline Non-profit & $\begin{array}{l}\text { An individual who reports working in a non-profit, international, or } \\
\text { funding agency. }\end{array}$ & 35 & $5.10 \%$ \\
\hline Student & An individual who reports being a student. & 28 & $4.08 \%$ \\
\hline Government & Individuals who report working in a government agency. & 3 & $0.44 \%$ \\
\hline Journalist & An individual who reports working as a journalist. & 2 & $0.29 \%$ \\
\hline
\end{tabular}

Table 5

Organizational Accounts Coded

\begin{tabular}{llrr}
\hline Role & Description & Count & $\%$ \\
\hline $\begin{array}{l}\text { Educational } \\
\text { institution } \\
\text { Non-profit }\end{array}$ & An account associated with a K-12 or higher education institution. & 67 & $29.52 \%$ \\
& $\begin{array}{l}\text { An account associated with a non-profit, international, or funding } \\
\text { agency. }\end{array}$ & 52 & $22.91 \%$ \\
Corporate & $\begin{array}{l}\text { An account associated with an organization outside of education, } \\
\text { non-profit, or government agencies. }\end{array}$ & 50 & $22.03 \%$ \\
Other & $\begin{array}{l}\text { An account in which the role could not be determined from available } \\
\text { data. }\end{array}$ & 32 & $14.10 \%$ \\
Government & An account associated with a government agency. & 12 & $5.29 \%$ \\
News & An account associated with a news agency. & 11 & $4.85 \%$ \\
Conference & An account associated with a conference. & 3 & $1.32 \%$ \\
\hline
\end{tabular}

First, to understand location differences, we mapped location data to individual tweets and discovered that $40.4 \%$ of the identifiable users were from the United States and that these users had created $48.4 \%$ of the tweets (cf. Figure 1 and Table 6). The next highest countries in this ranking were the United Kingdom (9.6\%) and Germany (9.2\%). This result indicated that the U.S. represented an extremely strong plurality in conversations surrounding openness, that all other countries combined only constituted a very slight majority, and that the Western world represented a strong majority. 

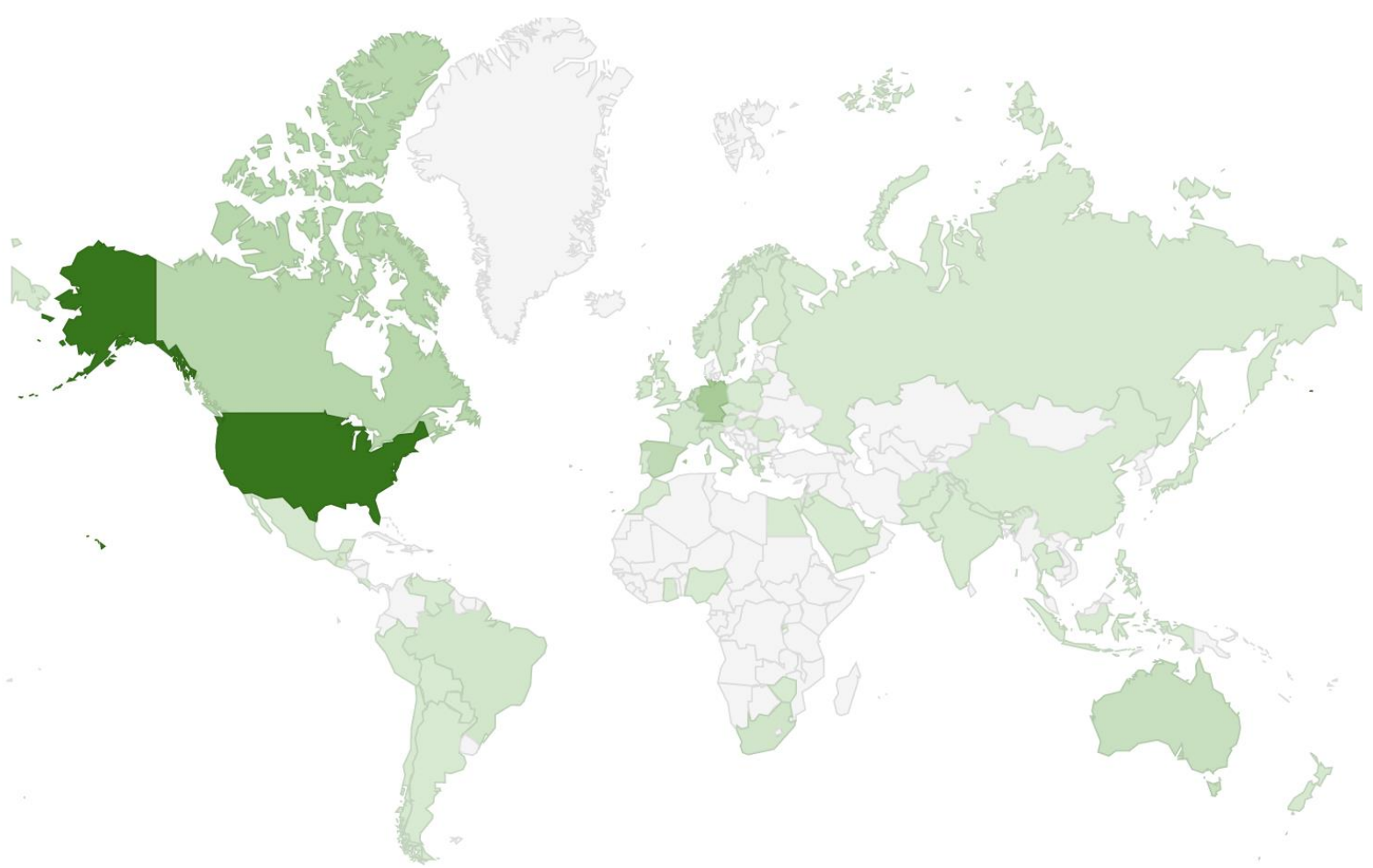

Figure 1. Target hashtag tweets by country.

Table 6

Top 10 Participating Countries by User Counts and Tweets

\begin{tabular}{|c|c|c|c|c|c|c|c|c|}
\hline \multirow[b]{2}{*}{ Country } & \multicolumn{2}{|c|}{ Users } & \multicolumn{2}{|c|}{ Total tweets } & \multicolumn{2}{|c|}{$\begin{array}{c}\text { Tweets with "open" } \\
\text { hashtags }\end{array}$} & \multicolumn{2}{|c|}{$\begin{array}{c}\text { Collected tweets per } \\
\text { user }\end{array}$} \\
\hline & Total & $\%$ & Total & $\%$ & Total & $\%$ & Total & "Open" \\
\hline United States & 345 & $40.4 \%$ & $3,360,641$ & $36.0 \%$ & 10,856 & $48.4 \%$ & $10,001.9$ & 32.3 \\
\hline $\begin{array}{l}\text { United } \\
\text { Kingdom }\end{array}$ & 82 & $9.6 \%$ & $1,124,944$ & $12.1 \%$ & 2,238 & $10.0 \%$ & $14,239.8$ & 28.3 \\
\hline Germany & 79 & $9.2 \%$ & 594,235 & $6.4 \%$ & 2,267 & $10.1 \%$ & $7,717 \cdot 3$ & 29.4 \\
\hline Canada & 50 & $5.8 \%$ & 516,639 & $5.5 \%$ & 1,194 & $5.3 \%$ & $10,332.8$ & 23.9 \\
\hline Spain & 42 & $4.9 \%$ & 819,879 & $8.8 \%$ & 455 & $2.0 \%$ & $20,497.0$ & 11.4 \\
\hline Netherlands & 40 & $4.7 \%$ & 348,489 & $3.7 \%$ & 906 & $4.0 \%$ & $8,712.2$ & 22.7 \\
\hline Australia & 27 & $3.2 \%$ & 146,122 & $1.6 \%$ & 462 & $2.1 \%$ & $5,411.9$ & 17.1 \\
\hline South Africa & 13 & $1.5 \%$ & 111,531 & $1.2 \%$ & 644 & $2.9 \%$ & $8,579.3$ & 49.5 \\
\hline Belgium & 13 & $1.5 \%$ & 72,246 & $0.8 \%$ & 37 & $0.2 \%$ & $5,557.4$ & 2.8 \\
\hline France & 12 & $1.4 \%$ & 157,136 & $1.7 \%$ & 183 & $0.8 \%$ & $13,094.7$ & $15 \cdot 3$ \\
\hline
\end{tabular}

Next, when we considered gender, we found that participating males exceeded females by $17.4 \%$ overall (cf. Figure 2). To determine whether the proportion of males to females changed from year to 
year, we grouped all "open" tweets by coded users according to year and found that participation percentages changed by year (cf. Figure $3 \&$ Table 7). Notably, males were overrepresented in 2010 at a 3 to 1 rate, but this disparity gradually disappeared when in 2013 female participation exceeded male participation (55\% to 45\%). This gain was gradually lost; however, as rates returned to their 2011 levels in 2016, with males out-tweeting females at a rate of 2 to 1.

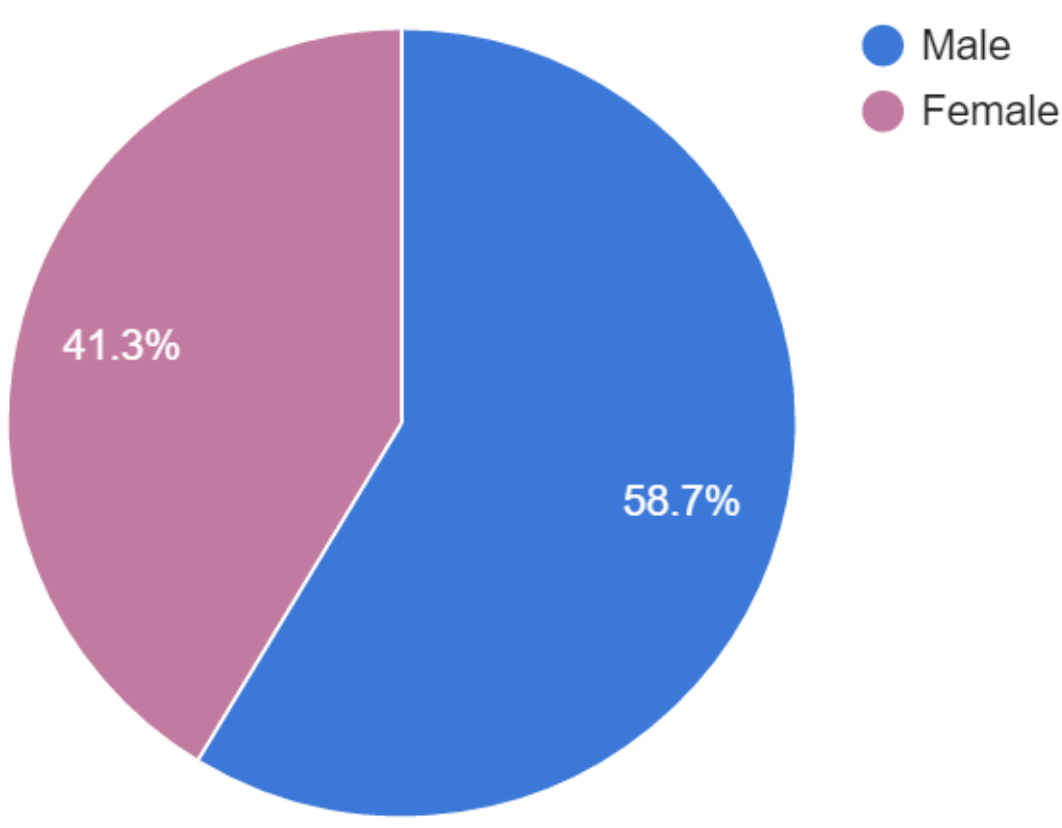

Figure 2. Twitter Participation by Gender.

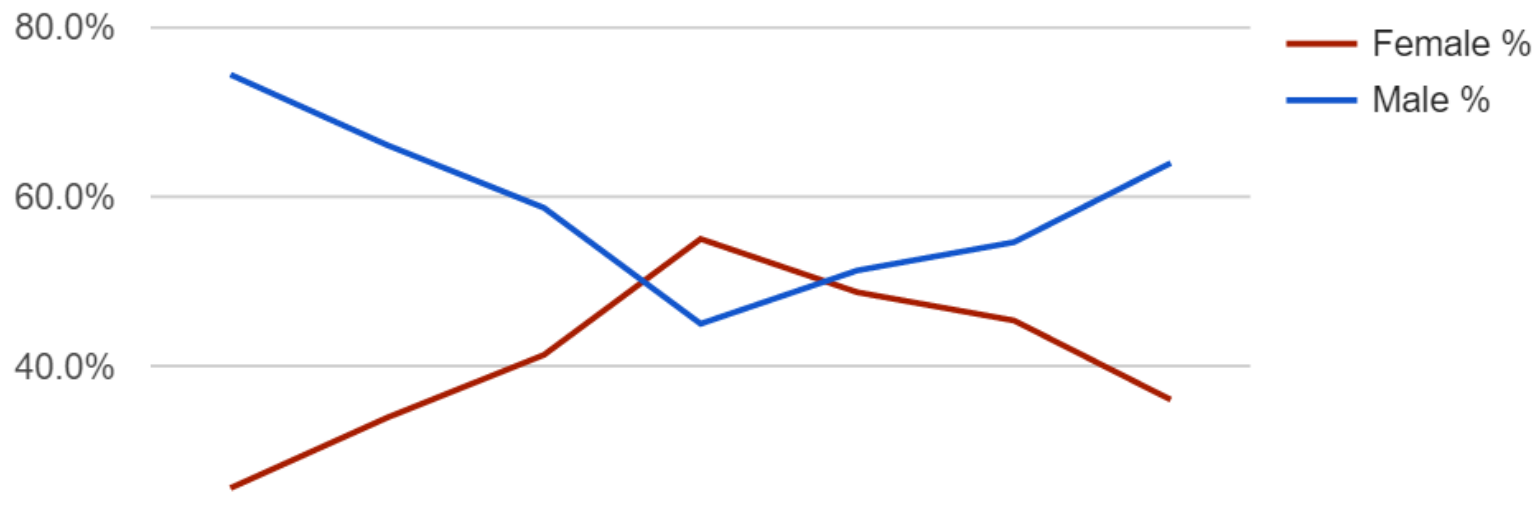

$20.0 \%$

\begin{tabular}{lllllll}
\cline { 2 - 5 } & $2010 \quad 2011$ & 2012 & 2013 & 2014 & 2015 & 2016
\end{tabular}

Figure 3. "Open” tweets by sampled user gender each year. 
Table 7

“Open” Tweets by Sampled User Gender Each Year

\begin{tabular}{lccc|ccc}
\hline & \multicolumn{2}{c}{ Female } & \multicolumn{3}{c}{ Male } \\
\cline { 2 - 6 } 2010 & Total & Female \% & \% Change & Total & Male \% & \% Change \\
2011 & 245 & $25.6 \%$ & - & 713 & $74.4 \%$ & $-8.3 \%$ \\
2012 & 437 & $33.9 \%$ & $8.3 \%$ & 852 & $66.1 \%$ & $-7.4 \%$ \\
2013 & 1048 & $41.3 \%$ & $7.4 \%$ & 1489 & $58.7 \%$ & $-13.7 \%$ \\
2014 & 1498 & $55.0 \%$ & $13.7 \%$ & 1225 & $45.0 \%$ & $6.3 \%$ \\
2015 & 1020 & $48.7 \%$ & $-6.3 \%$ & 1074 & $51.3 \%$ & $3.3 \%$ \\
2016 & 1240 & $45.4 \%$ & $-3.3 \%$ & 1493 & $54.6 \%$ & $9.4 \%$ \\
\hline Average & 568.4 & $43.5 \%$ & $-9.4 \%$ & 1050 & $64.0 \%$ & $-1.7 \%$ \\
\hline
\end{tabular}

Finally, we considered Twitter account type (i.e., individual or organizational) and role (e.g., corporate, educator, librarian) to determine whether user roles and participating organizations had changed over time. Results indicated that among individual accounts, corporate personnel and educators were most prevalent in 2010 but that this changed somewhat over time such that educators, instructional/educational developers, and non-profit personnel had become the most prevalent participants in 2016 (cf. Figure 4).

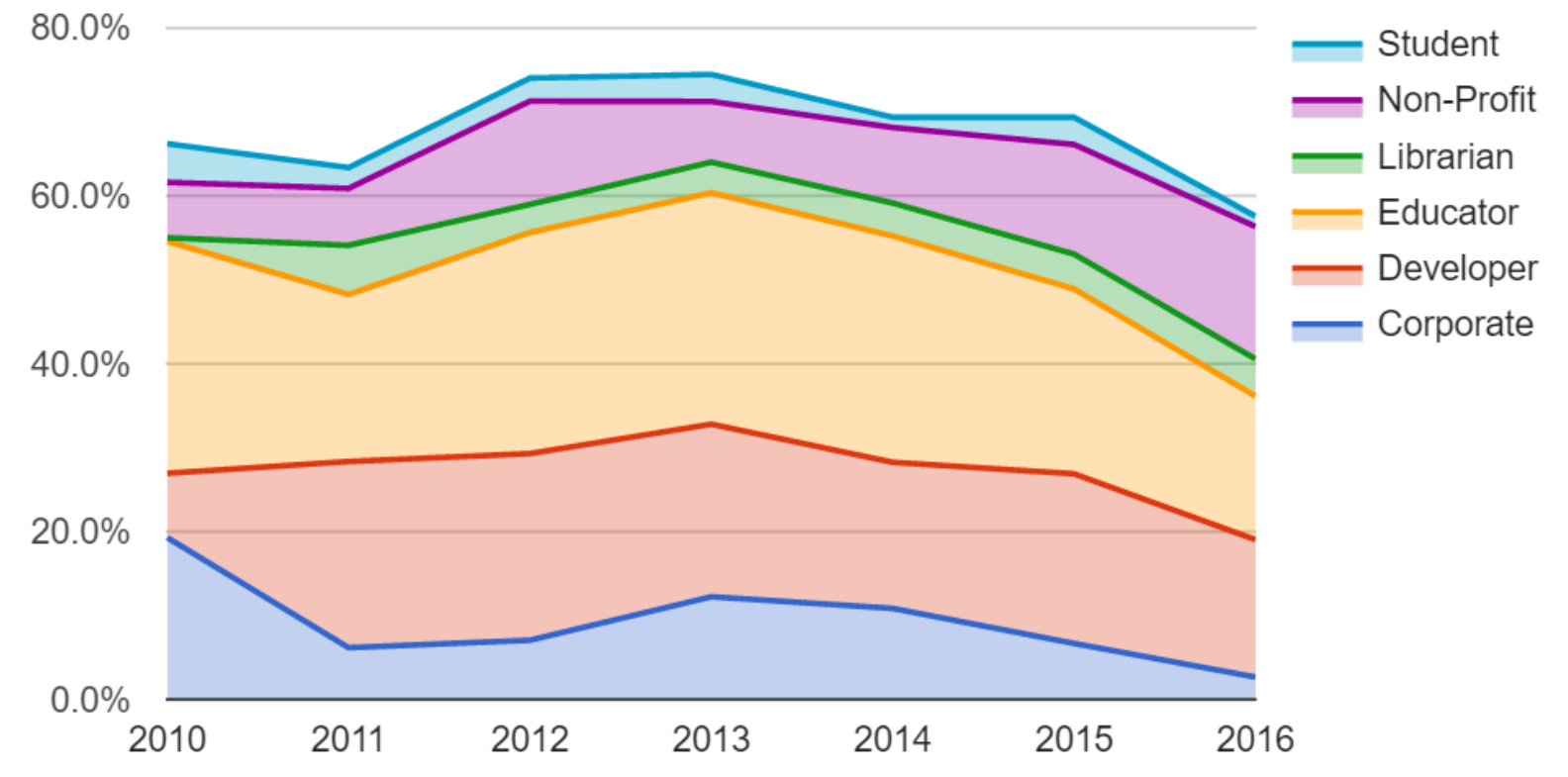

Figure 4. Individual account tweets by year and role.

With regard to organizational accounts, non-profits were the most prevalent in 2010, but this gradually fluctuated such that educational institutions became the most active by 2015 , and this continued into 2016 (cf. Figure 5). 


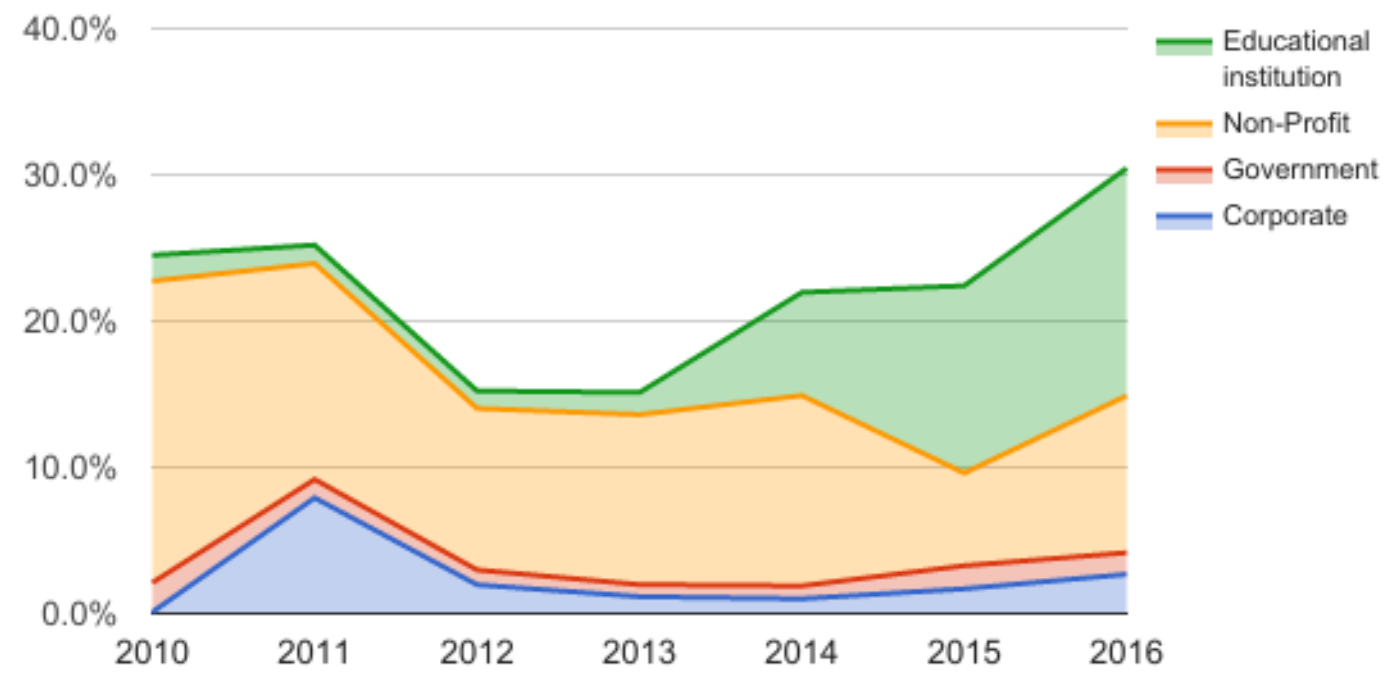

Figure 5. Organizational account tweets by year and role.

\section{RQ3. Discoursal Changes Over Time}

We approached time changes in three ways. First, we examined the history of tweet category frequencies for the Open Education Conference between 2010 and 2015. Descriptive analysis revealed that participation in the conference backchannel increased each year and that the percentage of tweets in the content category also steadily increased in almost every year, from $5.4 \%$ in 2010 to $11.9 \%$ in 2015 (cf. Table 8). Representation of tweets in the education and practice categories were extremely low, however, and only fluctuated slightly (less than $1 \%$ across all years). Furthermore, an examination of the top hashtags used at each year's conference revealed that \#oer was the most used hashtag at the conference between the years 2010-2015, with the exception of 2010-2011 when it came in second. Thus, we concluded that participants in that conference have historically focused their conversations around content and that this trend has only increased over time.

Table 8

Hashtag Groups by Year

\begin{tabular}{lcccl}
\hline Hashtag & Education & Content & Practice & Top hashtags used within the annual conference \\
\hline \#opened10 & $0.1 \%$ & $5.4 \%$ & $0.7 \%$ & drumbeat, oer, ukoer, p2pu \\
\#opened11 & $0.1 \%$ & $3.2 \%$ & $0.0 \%$ & ds106radio, oer, occupyopened11, edchat \\
\#opened12 & $0.2 \%$ & $5.6 \%$ & $0.0 \%$ & oer, ds106, ds106radio, ukoer \\
\#opened13 & $0.2 \%$ & $9.1 \%$ & $0.0 \%$ & oer, oerrhub, ds1o6radio, mooc \\
\#opened14 & $0.2 \%$ & $8.4 \%$ & $0.0 \%$ & oer, openaccess, liboer, oerrhub \\
\#opened15 & $0.3 \%$ & $11.9 \%$ & $0.4 \%$ & oer, bccampus, a11y, opentextbooks \\
\hline
\end{tabular}

Second, we applied this same process to all tweets in the dataset generally, grouping tweets by the year in which they were authored and providing descriptive statistics of hashtag category frequencies. Results indicated that content remained the most prominent topical category by a wide margin across 
all years (77.7\%) but that there had been a slow but steady increase in practice tweets from 20092016, with an average increase of $0.7 \%$ each year (cf. Figure 6).

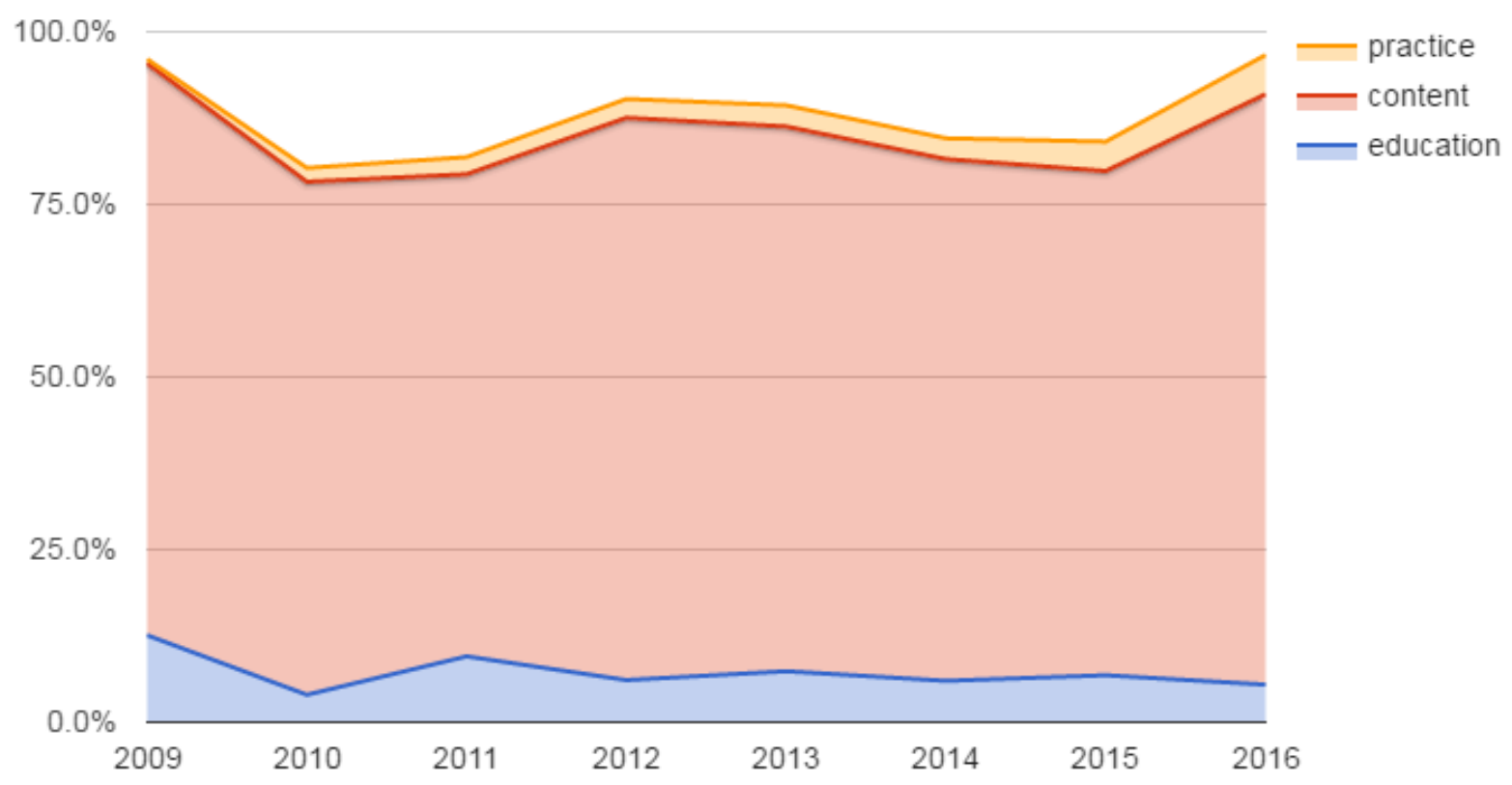

Figure 6. Tweet topical categories by year.

Third, we qualitatively coded the contents of a stratified random sample of tweets $(\mathrm{n}=1,061)$ for 2010-2016, which allowed for generalization to the dataset with a $95 \%$ confidence level at $+/-3 \%$. Two researchers first discussed a sample of 20 tweets to come to a common understanding of potential codes in the dataset. Next, one of the researchers coded 100 tweets, and the two researchers met to discuss the tweets and the codes. A codebook was generated, and all 1,061 tweets were coded by the first researcher using the codebook. If necessary, new codes were generated as needed, and all tweets were re-examined to explore whether they could be assigned to the new codes. Non-English tweets were also coded after being translated through Google Translate. The two researchers then met again, discussed the codes, and collaboratively reviewed the codes for consistency, accuracy, and potential bias. Sixty assigned codes were modified in this last step. Each tweet was assigned between one and three codes. The codes are shown in Table 9 with sample tweets being edited slightly to safeguard user identity. 
Table 9

Sample of Coding as Applied to Tweets

\begin{tabular}{|c|c|c|}
\hline Code & Description & Example \\
\hline Call for participation & $\begin{array}{l}\text { Tweet calls for } \\
\text { participation in } \\
\text { conference, journal, user } \\
\text { group, etc. }\end{array}$ & $\begin{array}{l}\text { The [open education conference] in held in [city] } \\
\text { Submit a proposal by [date] here: [URL] }\end{array}$ \\
\hline Funding & $\begin{array}{l}\text { Tweet provides } \\
\text { information related to } \\
\text { funding in the field. }\end{array}$ & $\begin{array}{l}\text { A new program provides funding for universities to } \\
\text { use OER to improve their courses: [URL] }\end{array}$ \\
\hline Inquiry & $\begin{array}{l}\text { Tweet asks a question or } \\
\text { makes an inquiry. }\end{array}$ & $\begin{array}{l}\text { Are there any good \# oer or \#openeducation } \\
\text { resources for [content area]? }\end{array}$ \\
\hline Media & $\begin{array}{l}\text { Tweet relates to press } \\
\text { coverage or media } \\
\text { announcement. }\end{array}$ & $\begin{array}{l}\text { What is the role of open educational resources? via } \\
\text { @guardian [URL] \#oer }\end{array}$ \\
\hline Moocs & $\begin{array}{l}\text { Tweet relates to Massive } \\
\text { Open Online Courses. }\end{array}$ & $\begin{array}{l}\text { [university] and [university] launch an educational } \\
\text { disruption: [URL] [series of open education } \\
\text { hashtags] }\end{array}$ \\
\hline Other & $\begin{array}{l}\text { Tweet is unrelated to } \\
\text { openness. }\end{array}$ & $\begin{array}{l}\text { Tying my best friends together by their bathing suit } \\
\text { tops. \#squareknot \#oep }\end{array}$ \\
\hline Pedagogy & $\begin{array}{l}\text { Tweet is related to open } \\
\text { pedagogical practices. }\end{array}$ & $\begin{array}{l}\text { Reflections on the practice of open education: } \\
\text { [URL] }\end{array}$ \\
\hline Platform & $\begin{array}{l}\text { Tweet announces, } \\
\text { promotes, or otherwise } \\
\text { highlights a digital } \\
\text { platform relevant to } \\
\text { openness. }\end{array}$ & $\begin{array}{l}\text { Guide on sharing LMS content and activities: } \\
\text { [URL] \#OER }\end{array}$ \\
\hline Policy & $\begin{array}{l}\text { Tweet highlights a } \\
\text { policy-related item. }\end{array}$ & $\begin{array}{l}\text { Campaign to encourage the adoption of openness } \\
\text { by the US Dept of Edu: [URL] \# edchat \#OER }\end{array}$ \\
\hline Reflection & $\begin{array}{l}\text { Tweet observes or } \\
\text { reflects on openness or } \\
\text { aspects of it, such as } \\
\text { open pedagogy. }\end{array}$ & The right to remix is important! [relevant hashtags] \\
\hline Research & $\begin{array}{l}\text { Tweet comments on or } \\
\text { links to research relevant } \\
\text { to openness. }\end{array}$ & $\begin{array}{l}\text { \#OER symposium \& research in [region of the } \\
\text { world]: [URL] }\end{array}$ \\
\hline Resource & $\begin{array}{l}\text { Tweet provides a } \\
\text { resource related to } \\
\text { openness. }\end{array}$ & $\begin{array}{l}\text { X tools for identifying open educational resources: } \\
\text { [URL] }\end{array}$ \\
\hline Textbooks & $\begin{array}{l}\text { Tweet relates to open } \\
\text { textbooks. }\end{array}$ & $\begin{array}{l}\text { Open textbooks in [region] lead to affordability: } \\
\text { [URL] \#OER \# highered }\end{array}$ \\
\hline
\end{tabular}

Results indicated that the most common tweet theme was resources (39.5\%) followed by reflections (23.3\%; cf. Figure 7). Pedagogy and policy were both uncommon (2.2\% and 3.1\%). Taken together, results from all three approaches revealed the same theme: most conversations historically had focused on content, and relatively few had dealt with practice or broader issues, but there were small, steady trends that suggested that these topics might be gaining traction. 


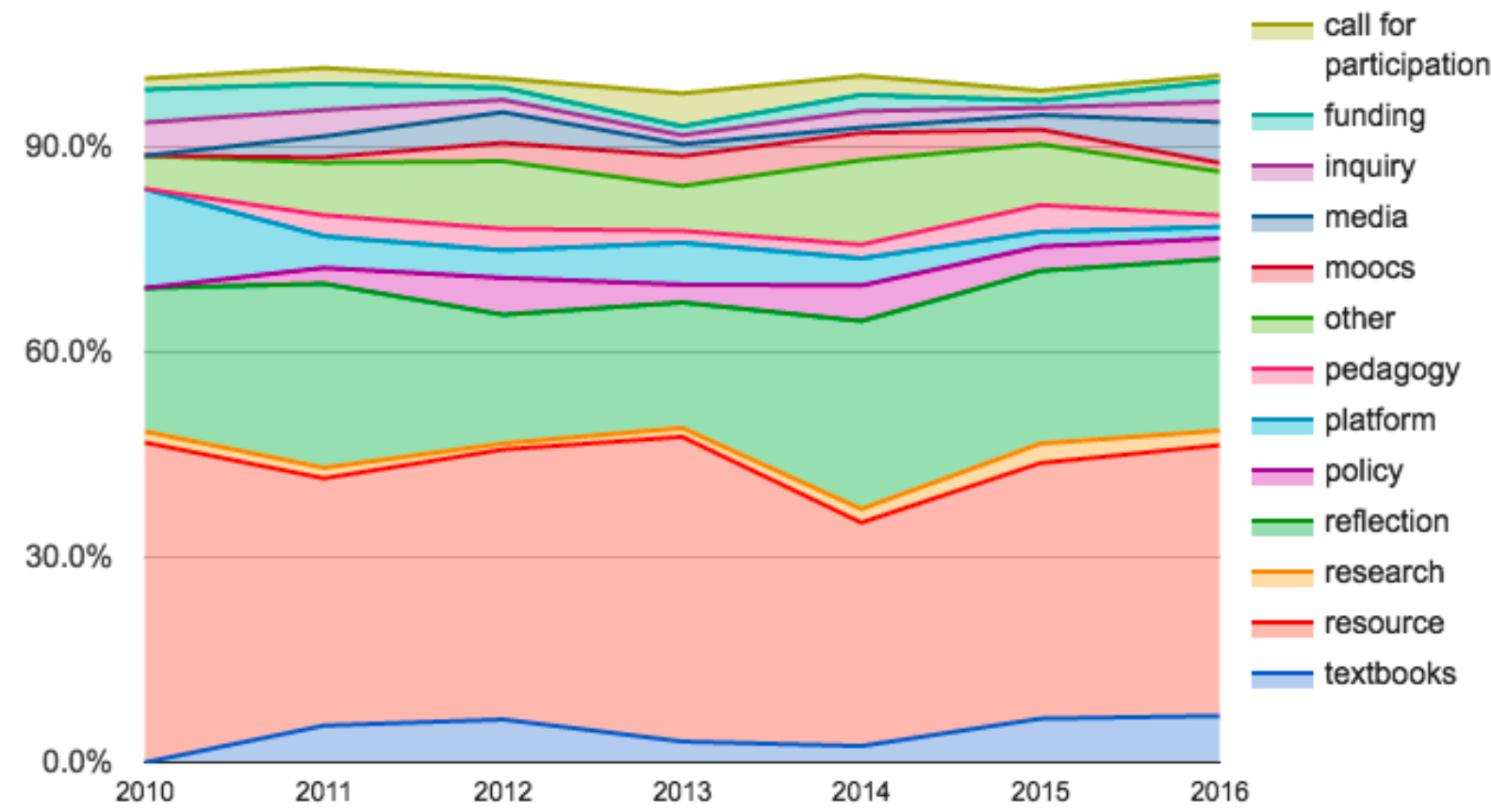

Figure 7. Qualitatively coded topics of tweets per year.

\section{Discussion and Implications}

These analyses show that openness on Twitter is largely discussed in terms of content. Over the sample period, open content dominated the discourse. This finding holds true even when tweet frequencies increased over time and participant frequencies and demographics changed somewhat. In other words, content monopolizes the discourse and persists in the face of changes in participation. This finding is reflective of the results reported by dos Santos (2008) who found that OER initiatives focused primarily on content provision, and open content currently seems to be central to the concept of open education. This finding may demonstrate the significance of open content to the openness movement and the ways that individuals come to learn about open education. On the other hand, while open content is important, this finding might also indicate how continued emphasis on open content might displace conversations around emerging aspects of open education, such as pedagogy and policy. Some questions that practitioners and researchers in the field may need to ask with respect to this finding include: Why is open content central to open education conversations? Is open content much easier to understand than other concepts associated with openness? Could open content be considered the Trojan horse of openness, in that it allows advocates and researchers to advance the cause of openness? Alternatively, we could ask whether this continued emphasis is detrimental to the open education movement. Do open educators become complicit in perpetuating content-centric pedagogical practices by continuing to focus on content as opposed to open pedagogies or open practices? If the community deems open pedagogy to be significant to the movement, we recommend greater advocacy and conversations around this aspect of openness on Twitter and elsewhere.

The open education community seems to recognize that a tension exists between open educational practices and OER, where the former represents a revolutionary approach to education and the latter 
represents an evolutionary stance (Jhangiani, 2017; Wiley, 2016). Both evolutionary and revolutionary approaches can be framed as "practical and effective means for achieving scholarly aims that are socially valuable" which is one of the assumptions underpinning the open movement (Veletsianos \& Kimmons, 2012, para. 21). However, the results presented here suggest that the discourse on Twitter focuses on pragmatism. Future research efforts may investigate the degree to which these results apply to the broader non-Twitter community, such as for example by surveying community members and identifying how open education is conceptualized by its members and how such conceptualizations have changed over time. If future research results confirm the findings presented here, the corollary is that open education researchers might be able to use Twitter to capture the pulse of the community. If future research disconfirms these findings, further investigation will be necessary to understand the role that Twitter serves in the open education community or the participants that make use of it. Nonetheless, educational research that uses large amounts of social media data as a source is an emerging methodological area, and there is a significant need to develop innovative techniques and approaches to analyzing these data sources including novel methods of extracting, interpreting, and handling of social media activity data (Weller, Bruns, Burgess, Mahrt, \& Puschmann, 2014).

While tweet codes reinforce the notion that content is significant to the open education community, they also reveal some additional interesting patterns. Significantly, we observe that Twitter serves multiple purposes in the community. For example, it circulates calls for participating in various happenings in the open education community, such as conferences, but also provides a space for individuals to reflect on the topic and share relevant resources. Seasoned social media users will find these results unsurprising. However, given the lack of studies examining use of Twitter over time, it is worth noting how these activities have shifted over the duration of this study. For instance, the time period investigated coincides with the rise and fall of interest in MOOCs, and this is revealed in the results which show that mentions of MOOCs were nearly non-existent in 2010, at their peak in 20122013, and have diminished drastically by 2016. A similar pattern emerges with open textbooks: While mentions were non-existent in 2010, they have emerged in popularity and appear prominently in the dataset in 2016. Thus, we see that time-series analyses of Twitter data might yield worthwhile insights to understand ebbs and flows in community discourse.

One significant caveat of this discussion relates to Twitter itself. Prior research (e.g., Kimmons \& Veletsianos, 2016; Veletsianos \& Kimmons, 2016) shows that individual scholars and higher education institutions mostly use Twitter to share resources and to broadcast information. Therefore, one could argue that Twitter, with its resource-sharing affordances, encourages individuals to share content. On the other hand, Twitter is agnostic as to the type of content that is being shared, and as a result, if conversations in the community were shifting to particular topics over time (e.g., greater emphasis on open textbooks or open practices), our analytic methods would have captured those shifts.

And finally, inherent in the idea of openness is the attitude that all should be able to participate, share, and reap the benefits of open communities. However, our results on the national and gender demographics of participants raises questions as to the ongoing diversity of the open education community. Notably, the U.S. dominates English-speaking conversations about openness, and though this might be somewhat expected given the relative size of that country, overrepresentation of males in the community should lead us to consider whether there are social or other barriers of entry for female participants. Interestingly, females gradually gained traction in the community and even overtook males in 2013, but this trend swiftly reversed the following year, and males now participate more than 
females at a rate of 1.8 to 1 . The reasons for this up- and then down-turn is unclear, but it may be connected to the gradual increase in educators up until 2013 and then the institutionalization of openness that began in 2014 as more educational institutions became involved. At any rate, if diversity of perspectives would be valued in any community, we would anticipate that this would be the case within open communities, so we suggest that leaders in this area should consider ways to better understand this issue and the reasons why many who should be participating in these conversations may not.

\section{Limitations and Delimitations}

There are two major limitations facing this study. First, the study began with bounding tweet collection by a set of a priori hashtags relevant to the topic. This was necessary for bounding and focusing our data collection processes, but it could be that there are openness conversations on Twitter occurring outside of these hashtags that were not included. Importantly, all of our included hashtags were anglophonic. For this reason, the reader should determine whether our a priori hashtags are representative enough to apply to openness generally or if there are any theoretical limitations in the study resulting from this necessary focus.

The second limitation involved the collection of historical Twitter data. There are restrictions imposed on the use of the Twitter API, and as a result, not all tweets posted can be retrieved for analysis. This study's results may underestimate the activity of Twitter use for openness as well as activity on particular hashtags. Nonetheless, this study provides an analysis of the most extensive and complete dataset of historical open education tweets to date and even if the dataset is necessarily incomplete, it is reflective of Twitter content and participation patterns.

\section{Conclusion}

In this paper, we investigated the discourse surrounding openness on Twitter and examined how that discourse developed over time. Most significantly, we found that more individuals are discussing more topics related to openness over time, but that the conversation seems to remain fixed on content. Is content the most powerful weapon that the open community has in its pursuit for democratizing education? Though our findings may be reflective of a certain subculture in the open community, like others (Deimann \& Farrow, 2013; OPAL, 2011; Veletsianos \& Kimmons, 2016; Weller, de los Arcos, Farrow, Pitt, \& McAndrew, 2015), we believe that the community should strive to diversify further and consider ways in which the discourses of open education may evolve to further enhance teaching and learning practices. 


\section{Acknowledgements}

This study was partially funded by an award from the Canada Research Chairs program.

\section{Data Availability}

Data from this study is available from http://roycekimmons.com/open datasets and is licensed under a Creative Commons Attribution (CC BY) 4.o International License.

\section{References}

Atkins, D., Seely Brown, J. \& Hammond, A. (2007, February). A review of the open educational resources (OER) movement: Achievements, challenges, and new opportunities. Report to The William and Flora Hewlett Foundation. Retrieved from http://www.hewlett.org/uploads/files/ReviewoftheOERMovement.pdf

Baker III, F. W. (2014). Open dialogue: A content analysis of the\# openeducation Twitter hashtag. Paper presented at the Association of Educational Communication Technology Annual Conference, Jacksonville, FL. Retrieved from http://www.fredwbaker.com/wpcontent/uploads/2015/02/Baker-Twitter-openeducation-AECT-2014.pdf

Belikov, O. M., \& Bodily, R. (2016). Incentives and barriers to OER adoption: A qualitative analysis of faculty perceptions. Open Praxis, 8(3), 235-246. Retrieved from https://doi.org/10.5944/openpraxis.8.3.308

Bissell, A. N. (2009) Permission granted: Open licensing for educational resources. Open Learning, 24(1), 97-106.

Bowness, S. (2017). The open educational resources movement is redefining the concept of online textbooks [Blog post]. University Affairs. Retrieved from http://www.universityaffairs.ca/features/feature-article/open-educational-resourcesmovement-redefining-concept-online-textbooks/

Bulfin, S., Pangrazio, L., \& Selwyn, N. (2014). Making 'MOOCs': The construction of a new digital higher education within news media discourse. The International Review of Research in Open and Distributed Learning, 15(5). doi: https://doi.org/10.19173/irrodl.v15i5.1856 
Deimann, M., \& Farrow, R. (2013). Rethinking OER and their use: Open education as Bildung. The International Review of Research in Open and Distributed Learning, 14(3), 344-360. doi: https://doi.org/10.19173/irrodl.v14i3.1370

dos Santos, A.I. (2008). The discourses of OERs: How flat is this world? Journal of Interactive Media in Education, 2008(1). doi: http://doi.org/10.5334/2008-11

Ehlers, U., \& Conole, G. (2010). Open educational practice: Unleashing the power of OER. Paper presented at the UNESCO Workshop on OER in Namibia, Windhoek. Retrieved from https://oerknowledgecloud.org/sites/oerknowledgecloud.org/files/OEP Unleashing-thepower-of-OER.pdf

Fischer, L., Hilton, J., Robinson, T. J., \& Wiley, D. A. (2015). A multi-institutional study of the impact of open textbook adoption on the learning outcomes of post-secondary students. Journal of Computing in Higher Education, 27(3), 159-172. doi: https://doi.org/10.1007/s12528-0159101-x

Hegarty, B. (2015). Attributes of open pedagogy: A model for using open educational resources. Educational Technology, 55(4), 3-11. Retrieved from https://upload.wikimedia.org/wikipedia/commons/c/ca/Ed Tech Hegarty 2015 article at tributes of open pedagogy.pdf

Hodgkinson-Williams, C., \& Paskevicius, M. (2012). The Role of Postgraduate Students in CoAuthoring Open Educational Resources to Promote Social Inclusion: A Case Study at the University of Cape Town. Distance Education, 33(2), 253-269. doi: https://doi.org/10.108o/01587919.2012.692052

Hylén, J. (2006). Open educational resources: Opportunities and challenges. OECD's Centre for Educational Research and Innovation. Retrieved from http://www.oecd.org/edu/ceri/37351085.pdf

Jhangiani, R. S. (2017). Pragmatism vs. Idealism and the Identity Crisis of OER Advocacy. Open Praxis, 9(2), 141-150. doi: https://doi.org/10.5944/openpraxis.9.2.569

Kernohan, D. (2015). "Keep the fire:" A trends analysis drawing on 12 years of open education. Paper presented at Open Education Conference 2015. Vancouver, Canada. Retrieved from http://followersoftheapocalyp.se/keep-the-fire-notes-on-my-opened15-presentation/

Kimmons, R. (2014). Developing open education literacies with practicing K-12 teachers. The International Review of Research in Open and Distributed Learning, 15(6).

Kimmons, R. (2015). Open online system adoption in K-12 as a democratizing factor. Open Learning: The Journal of Open, Distance and e-Learning, 3O(2), 138-151.

Kimmons, R. (2016). Expansive openness in teacher practice. Teachers College Record, 118(9). 
Kimmons, R., \& Veletsianos, G. (2016). Education scholars' evolving uses of twitter as a conference backchannel and social commentary platform. British Journal of Educational Technology, $47(3), 445-464$.

Kimmons, R., Veletsianos, G., \& Woodward, S. (2016). Institutional uses of Twitter in U.S. higher education. Innovative Higher Education, 42(2).

Kovanović, V., Joksimović, S., Gašević, D., Siemens, G., \& Hatala, M. (2015). What public media reveals about MOOCs: A systematic analysis of news reports. British Journal of Educational Technology, 46(3), 510-527. doi: https://doi.org/10.1111/bjet.12277

Lane, A., \& McAndrew, P. (2010). Are open educational resources systematic or systemic change agents for teaching practice? British Journal of Educational Technology, 41(6), 952-962. doi: https://doi.org/10.1111/j.1467-8535.2010.01119.x

Open Educational Quality Initiative (OPAL). (2011). OEP scape: The open educational practice landscape. Essen, Germany: ICDE Educational Quality Initiative.

Peter, S., \& Deimann, M. (2013). On the role of openness in education: A historical reconstruction. Open Praxis, 5(1), 7-14. doi: https://doi.org/10.5944/openpraxis.5.1.23

Pitt, R. (2015). Mainstreaming open textbooks: Educator perspectives on the impact of OpenStax College open textbooks. The International Review of Research in Open and Distributed Learning, 16(4). Retrieved from http://dx.doi.org/10.19173/irrodl.v16i4.2381

Veletsianos, G., \& Kimmons, R. (2012). Assumptions and challenges of open scholarship. The International Review of Research in Open and Distributed Learning, 13(4), 166-189.

Veletsianos, G., \& Kimmons, R. (2016). Scholars in an increasingly open and digital world: How do education professors and students use Twitter? The Internet and Higher Education, 30, 1-10.

Weller, M. (2014). Battle for open. Ubiquity Press. Retrieved from http://www.ubiquitypress.com/site/books/10.5334/bam/

Weller, M. (2016). Different aspects of the emerging OER discipline. Revista Educacao e Cultura Contemporanea, 13(31), 404-418. Retrieved from http://periodicos.estacio.br/index.php/reeduc/article/view/2321/1171

Weller, K., Bruns, A., Burgess, J. E., Mahrt, M., \& Puschmann, C. (2014). Twitter and society: An introduction. Digital Formations, 89. doi: http://dx.doi.org/10.3726/978-1-4539-1170-9

Weller, M., de los Arcos, B., Farrow, R., Pitt, B., \& McAndrew, P. (2015). The impact of OER on teaching and learning practice. Open Praxis, 7(4). doi: https://doi.org/10.5944/openpraxis.7.4.227

Wiley, D. (2007, August). Open education license draft [Blog post]. Retrieved from http://opencontent.org/blog/archives/355 
Wiley, D. (2014, March). The access compromise and the 5th R [Blog post] Retrieved from http://opencontent.org/blog/archives/3221

Wiley, D. (2016). Evolution vs revolution [Blog post]. Iterating Toward Openness. Retrieved from https://opencontent.org/blog/archives/4910

Wiley, D., Bliss, T. J., \& McEwen, M. (2014). Open educational resources: A review of the literature. In J. M. Spector, M. D. Merrill, J. Elen, \& M. J. Bishop (Eds.), Handbook of research on educational communications and technology (pp. 781-789). New York: Springer.

\section{Athabasca}

University

$$
\text { (c) (7) }
$$

